\title{
Porphyrin ring source can alter the outer membrane protein profile of non-typable Haemophilus influenzae
}

\author{
I. MACIVER, T. O’REILLY* and M. R. W. BROWN†
}

\begin{abstract}
Microbiology Research Group, Pharmaceutica/ Sciences Institute, Aston University, Aston Triangle, Birmingham B4 7ET
\end{abstract}

\begin{abstract}
Summary. Porphyrin ring source appears to alter the outer membrane protein (OMP) profile of some, but not all, non-typable (NT) Haemophilus influenzae strains isolated from sputum. When haemin was replaced with protoporphyrin IX, $41 \%$ of strains examined produced increased amounts of a polypeptide of $84 \mathrm{Kda}$ and new OMPs of either 120 or $150 \mathrm{Kda}$. Immunoblotting with paired patient's sera revealed that antibodies reactive with these proteins were present, demonstrating OMP antigenicity and expression in vivo and indicating that these isolates of NT $H$. influenzae may display an altered OMP phenotype when growing in the human lung.
\end{abstract}

\section{Introduction}

Non-typable (NT) Haemophilus influenzae strains are frequently cultured from purulent lower respiratory tract secretions of patients suffering from chronic bronchitis, bronchiectasis and cystic fibrosis (May et al., 1972; Smith et al., 1976; Murphy and Apicella, 1987). Several authors have examined the outer membrane protein (OMP) profile of NT $H$. influenzae (see Murphy and Apicella, 1987). Despite an apparently constant OMP pattern during the growth cycle (Murphy et al., 1983) and after repeated subculture of individual strains (Barenkamp, et al., 1982; Murphy et al., 1983), separate isolates of NT $H$. influenzae show great variation in OMP profiles (Loeb and Smith, 1980; Barenkamp et al., 1982; Murphy et al., 1983; Hansen et al., 1985). Although $H$. influenzae type b demonstrates some measure of phenotypic OMP response to altered conditions of culture (Loeb and Smith, 1980; Williams and Brown, 1985), notably haem limitation (Coulton and Pang, 1983; Stull, 1987) and iron restriction by use of transferrin (Herrington and Sparling, 1985) or iron depletion (Pidcock et al., 1988) in vitro, few data are available on alteration of OMP profiles amongst NT $H$. influenzae strains.

Although normal human sera usually contain antibodies that react with $H$. influenzae OMPs (Hansen et al., 1985; Spinola et al., 1986), probably

Received 13 March 1989; accepted 17 Aug. 1989.

*Present address: Pharma Research, K 125.1.04, Ciba-Geigy Ltd, Basel, Switzerland, CH-4002.

†Correspondence should be sent to Professor M. R. W. Brown. reflecting nasopharyngeal colonisation, convalescent sera from some patients with pneumonia caused by NT $H$. influenzae show quantitative increases in OMP-directed antibodies as well as the development of antibodies to OMPs not recognised by acute phase serum (Hansen et al., 1985). Conversely, nasopharyngeal colonisation of children with NT $H$. influenzae involving sequential acquisition and loss of strains with distinct OMP profiles appears to be accompanied by few changes in serum antibody response (Spinola et al., 1986); interestingly, this latter study demonstrated that OMPs not easily observed on sodium dodecyl sulphate-polyacrylamide gel electrophoresis (SDS-PAGE) could be detected by immunoblotting techniques, suggesting potent antigenicity of minor proteins. However, OMP antigens used in these studies (Hansen et al., 1985; Spinola et al., 1986) were of only one phenotype as expressed in vitro. Bacterial OMPs phenotypically expressed in vivo during growth in lungs have been shown to induce specific antibodies. These antibodies react with antigens present in bacteria grown in vivo and with antigens in bacteria grown in vitro under conditions that induce production of such OMPs (Anwar et al., 1984; Cochrane et al., 1988). Therefore, immunological recognition of novel OMP antigens phenotypically expressed in vitro may indicate production of these antigens in vivo. The purpose of this study was to examine the OMP phenotype response of NT $H$. influenzae resulting from substitution of porphyrin ring source and to determine expression of OMPs in vivo on the basis of the immunological responses detected in chronically infected patients. 


\section{Materials and methods}

\section{Bacterial strains and culture conditions}

The NT $H$. influenzae strains used in this study were isolated from purulent sputum samples from patients with bronchiectasis; samples of patients' serum were obtained at the same time. None of the patients was receiving antibiotics at the time. $H$. influenzae isolates were confirmed to be NT by failure to agglutinate with type-specific antisera. Bacteria were cultured in Brain Heart Infusion (BHI) Broth supplemented with growth yield excess NAD $(5 \mathrm{mg} / \mathrm{L})$ and with excess $(5 \mathrm{mg} / \mathrm{L})$ or growth yield limiting $(0.25 \mathrm{mg} / \mathrm{L})$ concentrations of either haemin or protoporphyrin IX (PPIX). To achieve ironrestricted conditions the iron chelator Desferal (CibaGeigy Ltd, Horsham Surrey) was added at a concentration of $30 \mu \mathrm{M}$ to cultures containing growth yield limiting concentrations of either haemin or PPIX. Growth was initiated by inoculating several colonies from chocolateagar plates into $200 \mathrm{ml}$ volumes of supplemented BHI contained in 1-L flasks fitted with polyurethane closures. Cultures were incubated at $37^{\circ} \mathrm{C}$ in an orbital shaking incubator $(180 \mathrm{rpm})$ in air, i.e., without $\mathrm{CO}_{2}$ enrichment. Growth was monitored by measurement of optical density at $470 \mathrm{~nm}$.

\section{Preparation of bacterial outer membranes}

Outer membranes (OMs) were prepared from stationary phase bacteria ( 15 -h cultures) by sarkosyl (sodium Nlauryol sarcosine; $2 \% \mathrm{w} / \mathrm{v}$ final concentration) as described previously (Kadurugamuwa et al., 1987), except that centrifugation at $180000 \mathrm{~g}$ was used to pellet the OMs. The protein content of each OM preparation was determined by the method of Lowry et al. (1951).

\section{SDS-PAGE and immunoblotting}

OMPs were separated by SDS-PAGE on $10 \%$ gels ( $5 \mathrm{~cm}$ in length) according to the method of Lugtenberg et al. (1975); $10 \mu \mathrm{g}$ of protein was loaded on to each well. Separated polypeptides were stained with Coomassie Blue and their molecular size was determined by comparison with standards of known molecular weight.

OMPs previously separated by SDS-PAGE were electrophoretically transferred on to nitrocellulose paper and antigenic sites were visualised by the method of Towbin et al. (1979). Although transfer of proteins was qualitatively complete, as judged by amido black staining of blotted nitrocellulose, transfer was quantitatively incomplete as judged by Coomassie Blue staining of blotted gels. Each $H$. influenzae isolate was probed with homologous patient's serum ( 1 in 25 dilution); protein Aperoxidase conjugate was used to visualise immune complexes.

\section{Results}

The effect of changing porphyrin source on the in-vitro growth of NT $H$. influenzae strain HM1 is shown in fig. 1; the growth responses of other isolates were similar (data not presented). Although substitution of haemin $5 \mathrm{mg} / \mathrm{L}$ with PPIX did not alter the final cell yield or growth rate, reduction of the initial haemin or PPIX concentration from $5 \mathrm{mg} / \mathrm{L}$ to $0.25 \mathrm{mg} / \mathrm{L}$ resulted in $50 \%$ and $54 \%$ reductions in final cell yield, respectively, but had no effect on growth rate (fig. 1). Increasing the porphyrin source concentration from $5 \mathrm{mg} / \mathrm{L}$ to $10 \mathrm{mg} / \mathrm{L}$ changed neither the growth rate nor the final cell yield (data not presented).

Fig. 2a shows that strain HM1 grown in the presence of PPIX displayed an altered OMP profile compared with cultures grown with excess haemin; a band or bands of $84 \mathrm{Kda}$ was (were) produced in increased amounts, and a novel 150-K da polypeptide appeared. Interestingly, despite loading equal amounts of protein, major OMPs from strain HM1 grown in the presence of PPIX (or growth limiting concentrations of haemin plus Desferal) appeared to be present in increased amounts compared with those from bacteria grown with excess haemin (figs. $2 \mathrm{a}$ and 3 ); however, it should be noted that this may also reflect more intense staining of OMPs produced during the former growth condition. The reason for this is unclear, but it appears to be a constant feature of membranes prepared from strain HM1, although it was not observed with any other strain examined. Strain HM2 also expressed OMP profile changes with an additional protein of $120 \mathrm{Kda}$ when grown in the presence of PPIX (fig. 2).

Supplementary experiments with strain HM1 (fig. 3) indicated that these OMP changes also occurred in bacteria grown in the presence of excess PPIX $(5 \mathrm{mg} / \mathrm{L})$ plus Desferal, and with growth yield limiting concentrations of PPIX $(0.25 \mathrm{mg} / \mathrm{L})$ in the presence or absence of Desferal, but not in haemin depleted $(0.25 \mathrm{mg} / \mathrm{L})$ media. Cultures in haemin depleted medium plus Desferal (fig. 3, lane 4) displayed increases in production of a band of $84 \mathrm{Kda}$ compared with cultures grown in excess haemin. A doublet at $84 \mathrm{Kda}$ appeared in membranes of cells grown with PPIX (with or without Desferal); however, this was inconsistently resolved (figs. 2a and 3). Additionally, a $150-\mathrm{Kda}$ protein was faintly visible in membranes of cultures grown in haemin-depleted medium plus Desferal, but this was expressed too weakly to be photographed, in contrast to those membranes obtained from cultures grown with PPIX with or without Desferal (fig. 3). Furthermore, increases in a minor polypeptide below the $84-\mathrm{Kda}$ protein (approximately $78 \mathrm{Kda}$ ) occurred during growth with PPIX or haemin in the presence of an iron chelator. 


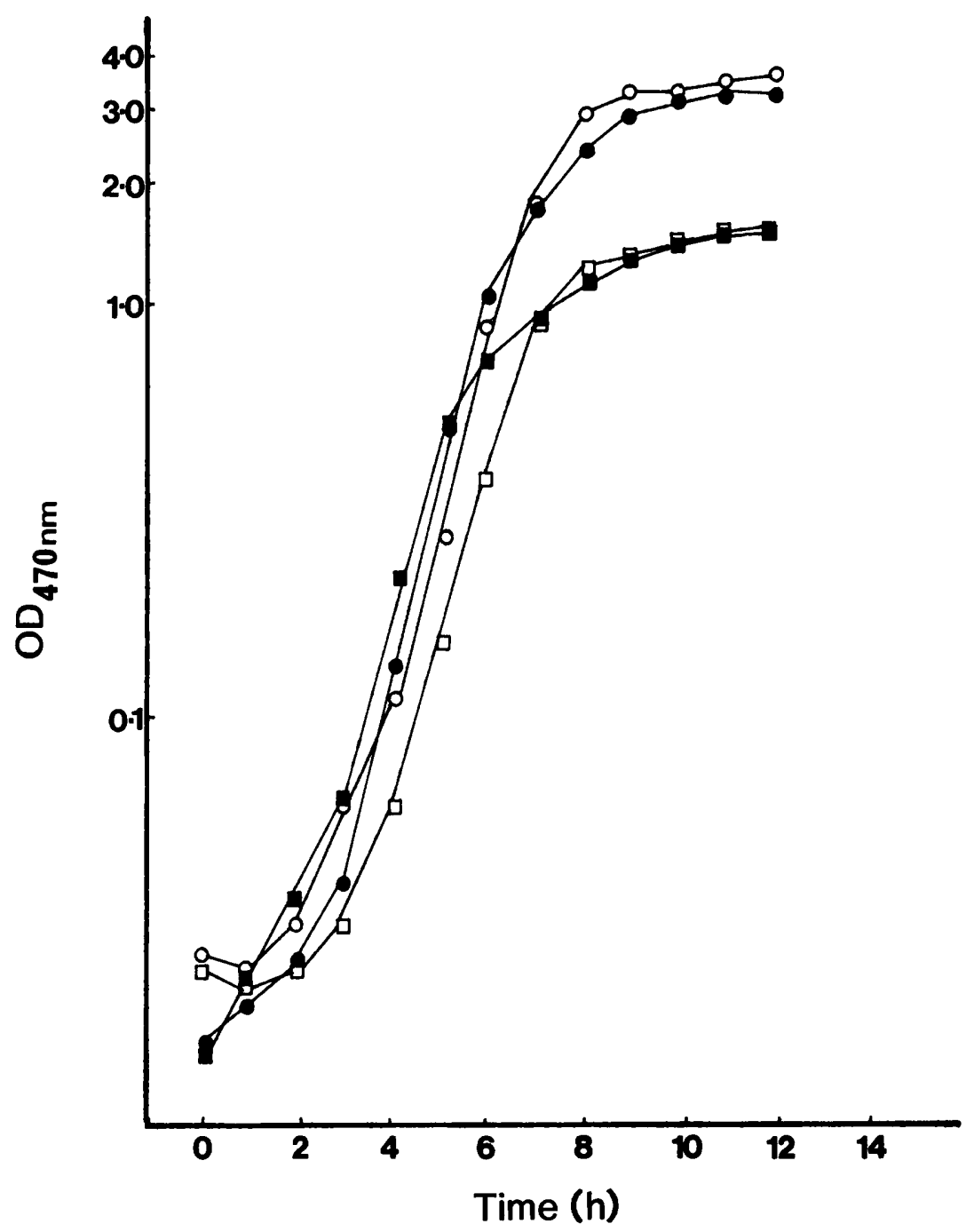

Fig. 1. The effect of initial haemin and PPIX concentration on the growth curve of $H$. influenzae strain $\mathrm{HM} 1$ at $37^{\circ} \mathrm{C}$. Bacterial growth in BHI containing haemin $(\mathcal{O}, \square)$ or PPIX $(O, \square) 5 \mathrm{mg} / \mathrm{L}(\mathcal{O}, O)$ or $0.25 \mathrm{mg} / \mathrm{L}(\square, \square)$, was monitored turbidimetrically.

No apparent changes in OMP profile were seen with several other NT $H$. influenzae isolates when haemin was replaced by PPIX (data not shown). Out of a total of 24 strains examined, $10(41 \%)$ displayed a phenotypic response to substitution of haemin with PPIX by alteration of the OMP profile; in the remaining $59 \%$, the OMP profile remained constant irrespective of the source of porphyrin ring. Amongst those strains in which a phenotypic change was demonstrated, 10 showed increases in the 84-Kda polypeptide and four showed increases in the $78-\mathrm{Kda}$ polypeptide, whereas three and seven expressed the novel 120$\mathrm{Kda}$ or $150-\mathrm{Kda}$ OMP, respectively.
Fig. 4 shows immunoblots of $H$. influenzae strains HM1 (fig. 4a) and HM2 (fig. 4b), demonstrating antibody activity directed against phenotypically expressed OMPs. Polypeptides of 150, 120 and 98 $\mathrm{Kda}$ present in membranes obtained from strain HM1 grown in media with PPIX were recognised by immune serum even though the $120-\mathrm{Kda}$ polypeptide was barely visible on the corresponding SDS-PAGE gel (fig. 2a). Although with strain HM2 the 84-Kda OMP(s) increased by growth with PPIX or by growth limiting concentrations of haemin was strongly recognised by immune serum (fig. 4b), the novel PPIX-induced polypeptides of 120 and $150 \mathrm{Kda}$ did not appear to be recognised. With the 

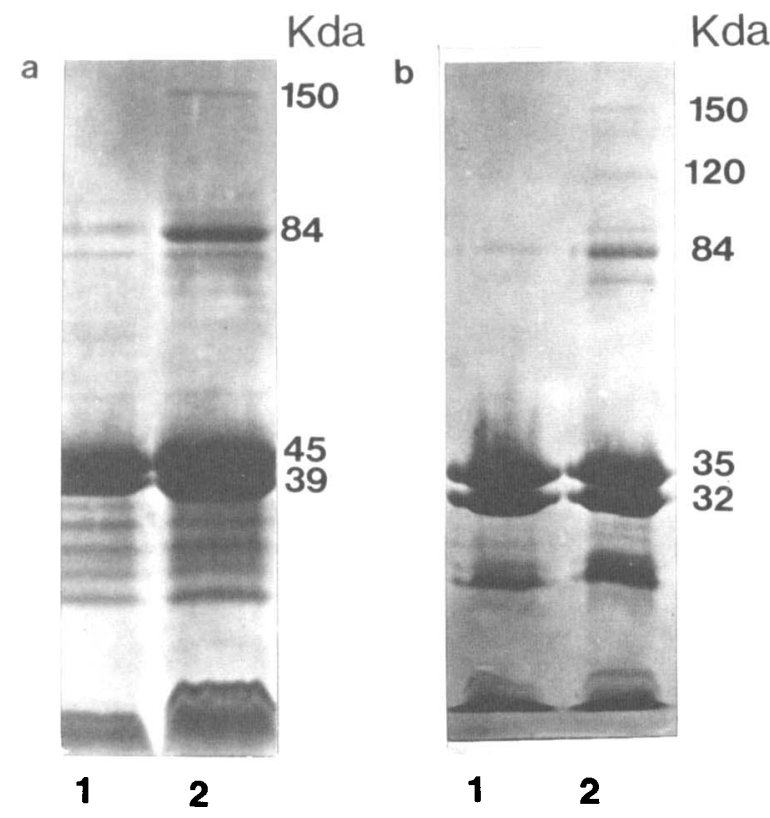

Fig. 2. Alteration of the OMP profile of NT $H$. influenzae by porphyrin ring source. Sarkosyl-extracted OMs were obtained from bacteria grown in the presence of haemin (1) or PPIX (2) and analysed by SDS-PAGE. Panel a represents the OMP profile of strain HM1, and panel $b$ the profile of strain HM2.

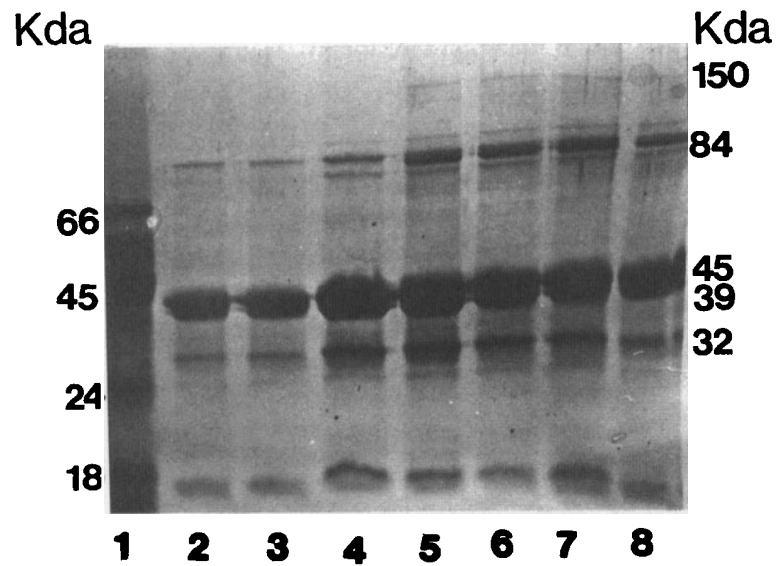

Fig. 3. Alteration of the OMP profile of $H$. influenzae strain HM1 by porphyrin ring source and iron restriction. Sarkosyl-extracted OMs were obtained from bacteria grown in the presence of excess haemin (lane 2), growth yield limiting haemin (lane 3), growth yield limiting haemin plus Desferal (lane 4), excess PPIX (lane 5), excess PPIX plus Desferal (lane 6), growth yield limiting PPIX (lane 7), and growth yield limiting PPIX plus Desferal. Mol. wt standards are shown in lane 1.

10 strains in which phenotypic OMP profile changes were demonstrated, all the paired patients' sera recognised the $84-\mathrm{Kda}$ band and the reaction was consistently stronger when antigen was prepared
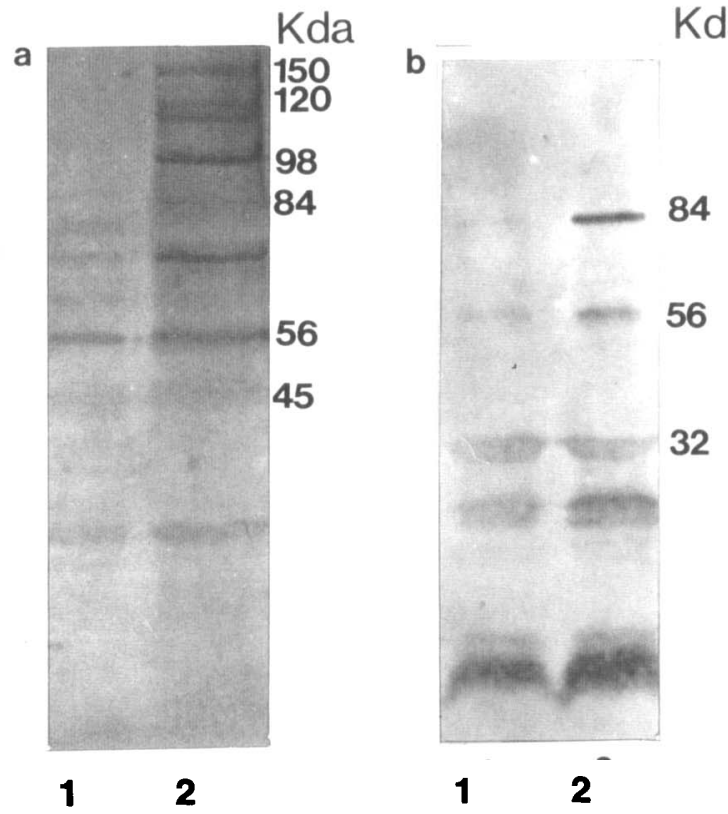

Fig. 4. Immunoblot of phenotypically altered OMPs of NT $H$. influenzae. OMPs from bacteria grown in the presence of excess $(5 \mathrm{mg} / \mathrm{L})$ haemin (1) or PPIX (2) were electrophoretically transferred to nitrocellulose and treated with homologous patient's serum; immune complexes were visualised with protein A peroxidase conjugate. Panel a represents the immunoblot obtained with OMPs from strain HM1 and panel b the immunoblot from strain HM2.

from bacteria grown with PPIX; $20 \%$ recognised the $120-\mathrm{Kda}$ and $60 \%$ the $150-\mathrm{Kda}$ OMP. The minor $78-\mathrm{Kda}$ band did not appear to be strongly recognised in any case. Interestingly, homologous sera recognised a $98-\mathrm{Kda}$ protein present in OMs prepared from strain HM1 grown with PPIX that was not visible in immunoblots from any other strain (fig. 4, lane 2).

\section{Discussion}

$H$. influenzae can acquire haem from a variety of substrates which are found in vivo, including haemoglobin, haemoglobin-haptoglobin, and haem-haemopexin (Stull, 1987; Pidcock et al., 1988). Whereas these serum proteins may be utilised by bacteria growing in blood, their availability in sputum is not known. However, increased serum transudation into the lung appears to be a feature of infections overlying chronic obstructive pulmonary disease (Stockley and Burnett, 1980) and may account for the presence in sputum of haem sources 
usable by $H$. influenzae. Both type b and NT $H$. influenzae strains can acquire iron from transferrin but not, generally, from lactoferrin (Herrington and Sparling, 1985; Pidcock et al., 1988; Schryvers, 1988). The latter is found in mucosal secretions and, unlike transferrin, is present in increased concentrations in fluid obtained by lung lavage following experimental challenge by gram-negative bacteria (La Force et al., 1986). The source of haem and iron for NT $H$. influenzae growing on mucosal surfaces or in the lung remains to be determined.

OMP changes have been shown to occur when $H$. influenzae type b strains are subject to haem or iron restriction. Different strains vary in response to haem limitation; they either produce $38-\mathrm{Kda}$ OMP (Stull, 1987) or increase production of a 43Kda OMP (Coulton and Pang, 1983). Iron restriction of type $b$ strains results in the induction of $a$ group of 90-95-K da OMPs in BHI broth (Herrington and Sparling, 1985) or in defined medium (Pidcock et al., 1988); production of additional OMPs appears to respond to the level of iron in the medium (Pidcock et al., 1988). Interestingly, growth with PPIX has been a prerequisite for studies involving iron restriction, but the effect of substitution of porphyrin ring source on type b strains is not clear (e.g. Stull, 1987; cf. Pidcock et al., 1988), although induction of a 73-Kda OMP in type b strains by PPIX has been reported (Williams and Brown, 1985). The changes described in these studies were not observed in the present study; this may be due to different experimental conditions, but may also be due to differences in the strains used. It should be noted that several strains isolated in the present study did not respond to the conditions tested; this was similar to the nonresponsiveness reported previously (Williams and Brown, 1985).

The present study has shown that the OMP profiles of some NT $H$. influenzae can change when the bacteria are grown in the presence of PPIX. Although not all strains of $H$. influenzae responded phenotypically to substitution of porphyrin ring source, production of the $84-, 120-$ and $150-\mathrm{Kda}$ OMPs appeared to respond to growth with PPIX. At least with strain HM1, the $84-\mathrm{Kda}$ band was resolved inconsistently as a doublet, the lower band apparently produced in response to PPIX utilisation and production of the upper band increased with PPIX utilisation or during growth with haemin in the presence of an iron chelator. This latter growth condition also increased the production of a78-K da OMP which also occurred during PPIX utilisation.

Some of these proteins (especially the 84-, 120and $150-\mathrm{Kda}$ proteins) appear to be antigenic, they were recognised by serum antibodies from chronically infected patients, and, therefore, are likely to be expressed by bacteria growing in vivo. However, it should be noted that the 120- and 150-Kda OMPs did not react consistently with homologous antisera and, although the reason for this is unclear, it may represent a failure of antibody induction, possibly due to a lack of antigen expression. The inconsistent resolution of the $84-\mathrm{Kda}$ doublet prevents the use of the immunoblotting procedure to discern whether a single component of the doublet, or both components, are antigenic and produced in vivo. Interestingly, OMPs not readily detectable by SDSPAGE were observed by immunoblotting when membranes prepared from bacteria grown with PPIX were used as antigen. However, these antibodies are probably not protective, at least in patients with bronchiectasis, as they are present in serum during the course of an infective exacerbation.

$H$. influenzae has the ability to utilise PPIX to form haem by the insertion of iron into the porphyrin ring by the enzyme ferrochelatase (White and Granick, 1963). However, it may be unlikely that an intracellular intermediate in mammalian haem synthesis such as PPIX (Israels et al., 1975) is a significant physiological substrate, compared with haemin, when $H$. influenzae is growing in vivo, so that the reason for induction of OMP changes that produce membranes more like those found in vivo by PPIX is unclear. It is tempting to speculate that growth utilising PPIX as a porphyrin source may provide a signal for the induction of iron regulated OMPs. This is supported by the observation that the addition of an iron chelator to media containing PPIX apparently causes no further OMP profile changes, compared with PPIX alone (fig. 3). Furthermore, although haemin can apparently provide for the entire iron requirement of $H$. influenzae (Pidcock et al., 1988), OMP profile changes similar to those induced by PPIX occur when Desferal is added to media containing growth yield limiting concentrations of haemin (fig. 3), conditions likely to reduce the concentration of iron available for the growth of $H$. influenzae. In this way, growth in media containing PPIX in place of haemin may mimic conditions of iron restriction, resulting in the expression of new OMPs. However, provision of PPIX as a porphyrin ring source may induce non-specifically a phenotypic change in vitro in some NT $H$. influenzae strains to produce OMP profiles more similar to those produced in vivo. The functions of these proteins, and the reasons for the apparent lack of their production by all strains, remain to be elucidated. 
This research was supported by grants from The Medical Research Council (UK) and The Cystic Fibrosis Research Trust awarded to MRWB and TO. TO is a grateful recipient of a Postdoctoral Fellowship from The Medical Research Council

\section{REFERENCES}

Anwar H, Brown M R W, Day A, Weller P H 1984 Outer membrane antigens of mucoid Pseudomonas aeruginosa isolated directly from the sputum of a cystic fibrosis patient. FEMS Microbiology Letters 24: 235-239.

Barenkamp S J, Munson R S, Granoff D M 1982 Outer membrane protein and biotype analysis of pathogenic nontypable Haemophilus influenzae. Infection and Immunity 36: 535-540.

Cochrane D M G, Brown M R W, Anwar H, Weller P H, Lam K, Costerton J W 1988 Antibody response to Pseudomonas aeruginosa surface protein antigens in a rat model of chronic lung infection. Journal of Medical Microbiology 27: 255261.

Coulton J W, Pang J C S 1983 Transport of hemin by Haemophilus influenzae type b. Current Microbiology 9: 9398.

Hansen M V, Musher D M, Baughn R E 1985 Outer membrane proteins of nontypable Haemophilus influenzae and reactivity of paired sera from infected patients with their homologous isolates. Infection and Immunity 47: 843-846.

Herrington D A, Sparling P F 1985 Haemophilus influenzae can use human transferrin as a sole source of required iron. Infection and Immunity 48: 248-251.

Israels L G, Yoda B, Schacter B A 1975 Heme binding and its possible significance in heme movement and availability in the cell. Annals of the New York Academy of Sciences 244: 651-661.

Kadurugamuwa J L, Anwar H, Brown M R W, Shand G H, Ward K H 1987 Media for study of growth kinetics and envelope properties of iron-deprived bacteria. Journal of Clinical Microbiology 25: 849-855.

LaForce F M, Boose D S, Ellison R T 1986 Effect of aerosolized Escherichia coli and Staphylococcus aureus on iron and ironbinding proteins in lung lavage fluid. Journal of Infectious Diseases 154: 959-965.

Loeb M R, Smith D H 1980 Outer membrane protein composition in disease isolates of Haemophilus isolates: pathogenic and epidemiological implications. Infection and Immunity 30: 709-717.

Lugtenberg B, Meijers J, Peters R, van der Hoek P, van Alphen L 1975 Electrophoretic resolution of the "major outer
(Canada). We thank Dr R.A. Stockley and Dr S.L. Hill (General Hospital, Birmingham, UK) for providing sputum and serum samples.

membrane protein" of Escherichia coli $\mathrm{K} 12$ into four bands. FEBS Letters 58: 254-258.

Lowry O H, Rosebrough N J, Farr A L, Randall R J 1951 Protein measurement with the folin phenol reagent. Journal of Biological Chemistry 193: 265-275.

May J R, Herrick N C, Thompson D 1972 Bacterial infection in cystic fibrosis. Archives of Diseases in Children 47: 908-913.

Murphy T F, Apicella M A 1987 Nontypable Haemophilus influenzae: A review of clinical aspects, surface antigens, and the human immune response to infection. Reviews of Infectious Diseases 9: 1-15.

Murphy T F, Dundas K C, Mylotte J M. Apicella M A 1983 A subtyping system for nontypable Haemophilus influenzae based on outer membrane proteins. Journal of Infectious Diseases 147: 838-846.

Pidcock K A, Wooten J A, Daley B A, Stull T L 1988 Iron acquisition by Haemophilus influenzae. Infection and Immunity 56 : 721-725.

Schryvers A B 1988 Characterization of the human transferrin and lactoferrin receptors in Haemophilus influenzae. Molecular Microbiology 2: 467-472.

Smith C B, Golden C A, Kanner R E, Renzetti A D 1976 Haemophilus influenzae and Haemophilus parainfluenzae in chronic obstructive pulmonary disease. Lancet 1: 12531255.

Spinola S M, Peacock J, Denny F W, Smith D L, Cannon J G 1986 Epidemiology of colonization by nontypable Haemophilus influenzae in children-a longitudinal study. Journal of Infectious Diseases 154: 100-109.

Stockley R A, Burnett D 1980 Alpha $_{1}$-antichymotrypsin in infected and noninfected sputum. American Review of Respiratory Disease 122 : 81-88.

Stull T L 1987 Protein sources of heme for Haemophilus influenzae. Infection and Immunity 55: 148-153.

Towbin H, Staehlin T, Gordon J 1979 Electrophoretic transfer of proteins from polyacrylamide gels to nitrocellulose sheets: procedure and some applications. Proceedings of the National Academy of Sciences of the USA 76: 4350-4354.

White D C, Granick S 1963 Hemin biosynthesis in Haemophilus. Journal of Bacteriology 85: 842-850.

Williams P, Brown M R W 1985 Influence of iron restriction on growth and the expression of outer membrane proteins by Haemophilus influenzae and $H$. parainfluenzae. FEMS Microbiology Letters 33: 153-157. 